\title{
the college
}

\section{Honorary Fellowships}

Nominations to the College's Honorary Fellowship will be discussed at the October meeting of the Education Training and Standards Committee.

The regulations of the College state under Bye-Law Section VI that

'Subject to the Regulations the College may elect as an Honorary Fellow any person, whether or not he is a member of the medical profession, who either is eminent in psychiatry or in allied or connected sciences or disciplines or has rendered distinguished service to humanity in relation to the study, prevention or treatment of mental illness or to subjects allied thereto or connected herewith or has rendered notable service to the College or to the Association.'

Nomination forms are available from Elizabeth Atkinson, Member Relations Manager (email: latkinson@rcpsych.ac. uk), to whom nominations for the Honorary Fellowship should be sent by 30 June 2008. Such nominations must contain recommendations by no fewer than six Members of the College and include full supporting documentation.

doi: 10.1192/pb.bp.108.019893

\section{CR147. Court Work}

Price: $£ 10.00$

Approved: Jul 2007

Published: Jan 2008

Number of pages: $39 \mathrm{pp}$

Review by: 2012

This report sets out the College's view on the complex issues of the involvement of psychiatrists in legal processes. The basic principles and recommendations provided are intended to be helpful to psychiatrists working within any legal system.
Psychiatrists are not expected to be legally trained, but if they are to function effectively when working within a legal framework they must be trained in using their psychiatric expertise and ethical understanding. This document will support all psychiatrists who work at the interface between psychiatry and the law. It aims to ensure that psychiatrists working in legal settings feel confident and prepared in their role, so that they can continue to make their enormous contribution to the welfare of their patients and the administration of justice.

The recommendations cover principles of practice for all psychiatrists as well as expert witnesses. Recommendations are also made about training for legal processes, both during psychiatric training and as an integral part of continuing professional development (CPD). The report therefore has implications for the training of all psychiatrists, their training schemes and their personal development plans.

(This report is not a textbook on how to deal with legal processes, nor does it specifically address variations between the legal systems of the different parts of the UK; although the scoping group's experience was largely of the English legal system.)

\section{Contents}

- Scoping Group on CourtWork

- Executive summary and recommendations

- Introduction

- Background

- The interface between psychiatry and the law

- Duties of a psychiatrist

- Duties of a psychiatric expert witness

- Training and continuing professional development

- The structure of reports

- The commissioning of reports and relation to employment
- Quality and supply

olumns
- Accreditation

- References

doi: 10.1192/pb.bp.108.019885

\section{The Royal College of Psychiatrists' Winter Business Meeting 2008}

The Winter Business Meeting was held at the Royal College of Psychiatrists on 25 January 2008. There were 33 members of the College present.

\section{Minutes}

The minutes of the Winter Business Meeting held at the Royal College of Psychiatrists on 23 January 2007 were approved as a correct record.

\section{Obituary}

The obituary list of members and associates who had died since the Annual General Meeting in 2007 was received.

\section{Election of Honorary Fellows}

The following were elected to the Honorary Fellowship for 2008:

The Rt Hon Baroness Murphy of Aldgate

DrAdam Roger Mark Freeman, FRCPsych

Steven S. Sharfstein, MD, MPA

Professor Jonathan Paul Shepherd, CBE DrAnthony Stephen Zigmond, FRCPsych

doi: 10.1192/pb.bp.108.020180 